\title{
Hallazgo de cuerpos escleróticos en un canino: sospecha de cromoblastomicosis cutánea
}

\author{
Sclerotic bodies found in a dog: suspected cutaneous chromoblastomycosis \\ V Silva ${ }^{1,2 *}, \mathrm{H}_{\text {Madrid }}{ }^{1}, \mathrm{~S}$ Anticevic ${ }^{3}$ \\ ${ }^{1}$ Programa de Microbiología y Micología, ICBM, Facultad de Medicina, Universidad de Chile, \\ ${ }^{2}$ Escuela de Tecnología Médica, Facultad de Medicina, Universidad Mayor. \\ ${ }^{3}$ Clínica de Pequeños Animales, Facultad de Ciencias Pecuarias y Veterinarias, Universidad de Chile.
}

\section{SUMMARY}

A female canine patient presented a history of chronic generalized pruritus. In the dermatological examination, scaly alopecic lesions with hyperkeratosis were detected on the inner posterior face of both thighs. Microscopical examinations of skin scrapings showed the presence of sclerotic bodies, diagnostic elements of chromoblastomycosis, a mycotic infection rare in Chile and not previously described in dogs. Topical antifungal therapy with benzoyl peroxide resulted in clinical and mycological cure of lesions.

Palabras clave: cuerpos escleróticos, cromoblastomicosis, micosis.

Key words: sclerotic body, chromoblastomycosis, mycosis.

\section{INTRODUCCION}

La cromoblastomicosis, también conocida como cromomicosis, es una infección fúngica que puede involucrar piel y tejidos subcutáneos, produciendo un amplio espectro de lesiones, que van desde placas eritematosas y descamativas, similar a una dermatitis, hasta la formación de cuerpos vegetativos verrugosos que afectan fundamentalmente las extremidades (Kwon-Chung y Bennett 1992, Sidrim y col 2004). Esta micosis posee distribución cosmopolita, siendo más frecuente en nuestro continente en regiones de clima tropical y subtropical tales como México, Brasil y Venezuela (Kwon-Chung y Bennett 1992, Sidrim y col 2004). La etiología de la cromoblastomicosis es compartida por una diversidad de hongos dematiáceos, destacando por su frecuencia algunas especies de los géneros Fonsecaea, Phialophora y Cladophialophora, entre otros (Kwon-Chung y Bennett 1992, De Hoog y col 2000, Salgado y col 2004, Sidrim y col 2004). El reservorio de estos organismos está constituido principalmente por el suelo y materia vegetal, pudiendo penetrar accidentalmente en los tejidos del hospedero mediante traumatismos (Iwatsu y col 1981, Salgado y col 2004).

Una particularidad que presenta el diagnóstico de esta micosis es la observación en el material clínico de es-

Aceptado: 03.10.2006.

* Correspondencia: Dr. Víctor Silva, Escuela de Tecnología Médica, Facultad de Medicina, Universidad Mayor, Camino La Pirámide 5750, Huechuraba, Santiago. Fono: (56-2) 328.1232. E-mail: victorsilva@umayor.cl tructuras fúngicas globosas a ovoideas parduscas de gruesas paredes oscuras o dematiáceas, debido a la presencia de melanina en su pared, con septos en distintos planos, las cuales son denominadas "cuerpos escleróticos", también conocidos como "cuerpos muriformes" o "cuerpos de Medlar", que son producidos exclusivamente en parasitismo y sólo en la cromoblastomicosis (Kwon-Chung y Bennett 1992, Sidrim y col 2004). Por otro lado, estos agentes, así como otros hongos pigmentados negros, pueden causar distintos cuadros clínicos como feohifomicosis y tinea nigra, diferenciándose estos últimos por la presencia en el material clínico de hifas septadas dematiáceas más o menos irregulares y/o células similares a levaduras, sin la presencia de cuerpos escleróticos (Fondati y col 2001, Sidrim y col 2004, Silva y Godoy 2004).

Pese a que distintas especies de mamíferos son potenciales hospederos de los hongos responsables de la cromoblastomicosis, la información sobre la frecuencia de esta enfermedad en animales es escasa, existiendo pocos relatos en la literatura que incluyen sólo a batracios (Bube y col 1992, Juopperi y col 2002) y caballos (Simpson 1966, Abid y col 1987). En Chile, el cuadro clínico de cromoblastomicosis ha sido reportado solamente en un paciente humano a través de estudio histopatológico (Oddó y Lobos 1988). Sin embargo, la especie Phialophora verrucosa, agente de esta micosis, ha sido aislada desde muestras de suelo en la zona norte y desde pelaje de perros aparentemente sanos de la zona costera de la V Región del país (Piontelli y col 1982, Piontelli y Toro 1987).

El motivo de esta comunicación es presentar el hallazgo de cuerpos escleróticos, estructuras fúngicas 
diagnósticas de cromoblastomicosis, en muestra clínica de un perro que presenta lesiones alopécicas descamativas con hiperqueratosis en ambos muslos, pudiendo tratarse del primer caso animal documentado en Chile.

\section{DESCRIPCION DEL CASO CLINICO Y DISCUSION}

Canino mestizo, hembra, de dos años de edad, se presenta a consulta médica el día 21 de abril de 2005 por prurito generalizado, intenso y de curso crónico en el Hospital Clínico Veterinario de la Universidad de Chile. La paciente vive en casa de sus dueños, en Santiago de Chile, con reclusión intradomiciliaria, donde convive con una mascota felina y en ocasiones tiene contacto con otro canino que habita en el patio de la casa, ambos clínicamente sanos y con sus registros sanitarios al día. La paciente recibe alimentación comercial (Dog-Chow). Su última desparasitación oral se realizó con Praziquantel 25 mg, Emboato de Pyrantel 72 mg y Febantel 75 mg en marzo de 2005 y la vacunación séxtuple y antirrábica se efectuó el 18 de abril de 2005. El examen físico y la auscultación fueron normales.

Al examen dermatológico, se evidencia pelaje opaco, seborreico, de fácil depilación a la tracción, con una rarefacción pilosa generalizada, áreas de alopecía hiperpigmentadas e hiperqueratinocíticas con borde eritematoso, circunscritas en la cara interior-caudal de ambos muslos (figura 1). Además, se observan ambos conductos auditivos externos eritematosos, con pápulas e hipertricosis y furunculosis perianal. La paciente presentó prurito en más de cinco ocasiones durante la consulta, manifestando lamido abdominal, interdigital y perianal, así como rasquido de la cabeza con las garras de las extremidades posteriores.

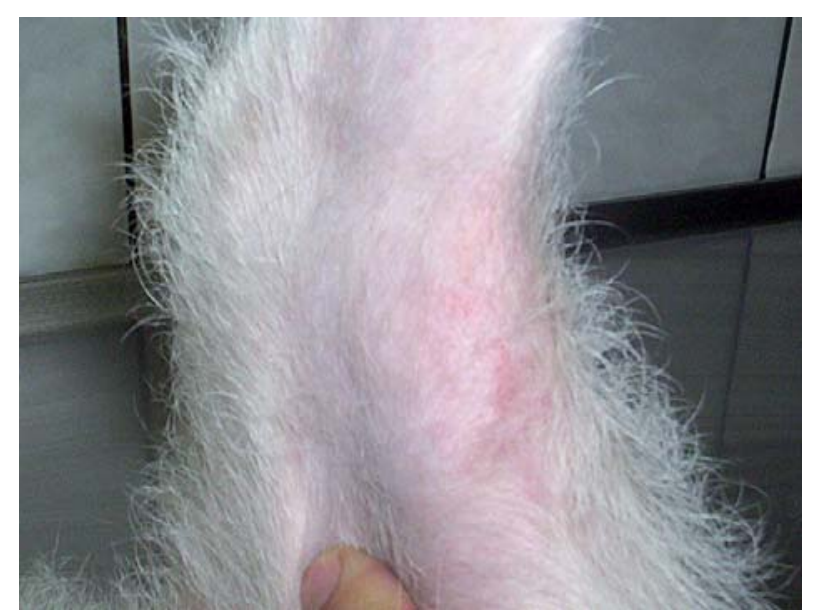

Figura 1. Cara interior del muslo que muestra lesión seborreica, pelaje opaco y áreas de alopecía hiperpigmentadas e hiperqueratinosíticas con borde eritematoso.

Seborrhoeic lesion on inner face of the thigh with dull hair, hyperpigmented alopecia areas and hyperkeratosis with erythematous border.

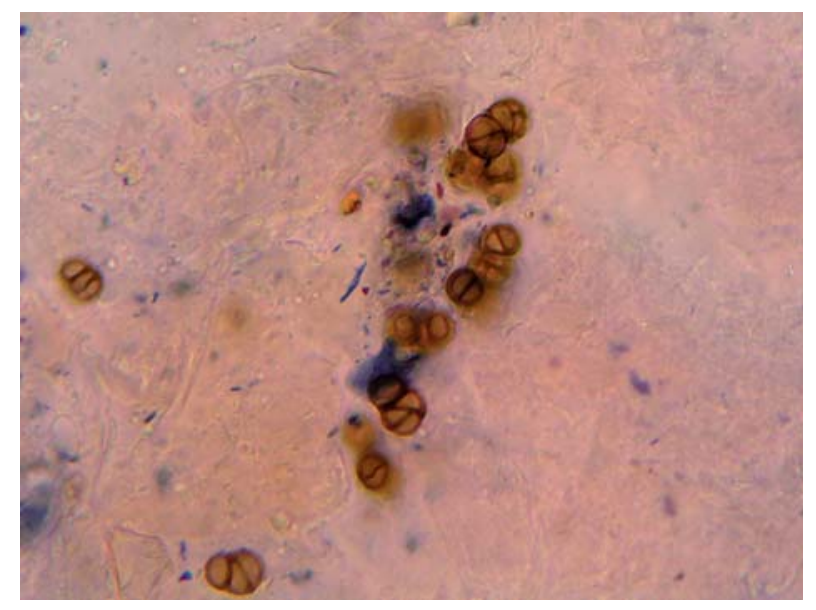

Figura 2. Microfotografía del examen microscópico directo de material clínico, evidenciando la presencia de estructuras globosas a ovaladas de color marrón, paredes gruesas y oscuras, con septos en distintos planos, identificadas como cuerpos escleróticos sobre los queratinocitos (aumento 400X).

Microphotograph of direct microscopic examination from clinical sample showing the presence of orbicular to oval dark pigmented cells with thick walls and cross-septated, identified as sclerotic bodies on skin scales (400X).

Estudio micológico, tratamiento y evolución. Se procedió a la recolección de muestras de pelos y escamas de piel desde los bordes de las zonas de alopecía. Parte de la muestra fue destinada al examen microscópico directo con $\mathrm{KOH}$ al 20\% más tinta Quinck Parker permanente de color negro en proporción de 3:1, que reveló la presencia de elementos celulares globosos y ovalados de color marrón, pared gruesa oscura, con septos en distintos planos, agrupados y solitarios entre los queratinocitos, siendo identificados como cuerpos escleróticos (figura 2). Los cultivos realizados en agar Sabouraud glucosado con y sin cloranfenicol $(100 \mathrm{mg} / \mathrm{l})$ incubados a 25 y $37^{\circ} \mathrm{C}$, sólo presentaron crecimiento de hongos contaminantes, identificados como Aspergillus flavus y Paecilomyces spp. El examen parasitológico fue negativo.

Ante la observación de cuerpos escleróticos, elementos diagnósticos de cromoblastomicosis y la sospecha clínica de una dermatosis concomitante con base alérgica, con sobreinfección bacteriana, asociada a un desorden queratoseborreico secundario, se estableció un esquema terapéutico consistente en una prueba histamínica con hidroxicina en dosis de $2,2 \mathrm{mg} / \mathrm{kg}$ cada 8 horas, una dieta hipoalergénica en base a proteína hidrolizada, con modificación de su peso molecular (Royal Canin hipoalergénico ®), flucloxacilina en dosis de $2,2 \mathrm{mg} / \mathrm{kg}$ cada 8 horas y baños con champú de peróxido de benzoilo al $2,5 \%$, el cual posee una acción queratolítica, queratoplástica y antimicótica.

Al primer control, realizado el día 3 de mayo de 2005, se observaron lesiones pápulo-costrosas y collaretes epidérmicos abdominales, habiendo remisión de las zonas 
hiperpigmentadas de la cara interna de los muslos. Una nueva muestra cutánea evidenció la ausencia de cuerpos escleróticos al examen microscópico directo con cultivo micológico negativo. Como el prurito no había disminuido con el tratamiento, el antihistamínico fue reemplazado por cetirizina en dosis de $10 \mathrm{mg}$ totales una vez al día por 14 días.

El segundo control se realizó el día 29 de julio de 2005 , constatando que las lesiones dérmicas habían remitido, pero el prurito se mantuvo con igual magnitud. Se suspendió la terapia antihistamínica durante 3 semanas para evitar la interferencia de los medicamentos con un test de intradermorreacción. La dieta de la paciente se modificó a un alimento de mantención para adulto marca Royal Canin ${ }^{\circledR}$ debido a que no hubo diferencias que justificaran la hipótesis de una hipersensibilidad alimentaria. Aunque se consiguió remisión clínica y micológica de las lesiones cutáneas, el cuadro dermatológico de prurito generalizado continuó en estudio, realizándose un test de intradermorreacción el día 2 de agosto de 2005, arrojando reacción positiva para Dermatophagoides farinae, polen de Artemisa vulgaris y epitelio de Felis domesticus.

En Chile, la cromoblastomicosis es muy infrecuente, encontrándose en la literatura nacional sólo un caso autóctono, documentado por examen histopatológico en un paciente humano a fines de la década del 80 (Oddó y Lobos 1988). Esta baja casuística local contrasta con estudios ambientales, donde se ha conseguido el aislamiento de hongos dematiáceos como Phialophora verrucosa, especie reconocida en otras latitudes como agente etiológico de cromoblastomicosis, desde suelos de la zona norte (Piontelli y col 1982) y desde el pelaje de dos perros aparentemente sanos en el sector costero de la zona central del país (Piontelli y Toro 1987). Nuestro paciente ha vivido siempre en la ciudad de Santiago, cuyo clima es de tipo templado cálido con estación seca prolongada y lluvias invernales que alcanzan un promedio anual cercano a los $300 \mathrm{~mm}$.

Clínicamente la cromoblastomicosis está caracterizada por lesiones de curso crónico, bajo la forma de nódulos o placas hiperqueratósicas, indoloras, con o sin prurito, que comienzan en el sitio de un trauma menor, extendiéndose por contigüidad, lentamente, evolucionando hasta la formación de extensas vegetaciones que comprometen funcionalmente el miembro afectado en el curso de años e incluso décadas (Kwon-Chung y Bennett 1992, Salgado y col 2004, Sidrim y col 2004). En las lesiones observadas en nuestra paciente están presentes la hiperqueratosis y el prurito, no observándose formaciones verrugosas deformantes, debido probablemente a un corto tiempo de evolución acompañado de un diagnóstico precoz que permitió instaurar un tratamiento oportuno.

El diagnóstico de la cromoblastomicosis se realiza rápidamente en el examen microscópico directo del ma- terial clínico, al observar la presencia de estructuras características, denominadas cuerpos escleróticos (KwonChung y Bennett 1992, Sidrim y col 2004), los cuales fueron identificados sobre los queratinocitos de nuestra paciente canina. Cabe destacar la rápida mejoría de las lesiones de nuestra paciente ante el tratamiento antimicótico tópico empleado, que podría ser explicado por la rápida consulta que mantuvo un compromiso incipiente y superficial del cuadro, lo que contrasta con la lenta y muchas veces insatisfactoria respuesta clínica reportada para esta enfermedad en otras especies de mamíferos incluyendo el hombre, en el que a menudo se realiza el diagnóstico después de un largo período de evolución, cuando existe un compromiso subcutáneo, tras el cual la administración de fármacos sistémicos y la remoción quirúrgica del tejido infectado no siempre consiguen la cura (Kwon-Chung y Bennett 1992, Sidrim y col 2004).

Esta comunicación alerta al médico veterinario y al profesional de laboratorio sobre la presencia de cuerpos escleróticos en lesión cutánea de un canino en nuestro medio, cuyo diagnóstico y tratamiento precoz se vio acompañado de cura clínica y microbiológica. La presencia de cuerpos escleróticos es característica en cromoblastomicosis, por lo que este hallazgo puede representar el primer caso canino documentado en Chile.

\section{RESUMEN}

Una paciente canina se presenta a consulta con prurito generalizado de curso crónico. El examen dermatológico evidencia lesiones alopécicas descamativas con hiperqueratosis en la cara interior caudal de ambos muslos. El examen microscópico directo de muestra de escamas cutáneas con $\mathrm{KOH}$ más tinta Quinck Parker evidencia la presencia de cuerpos escleróticos, elementos diagnósticos de cromoblastomicosis, una patología micótica muy infrecuente en Chile y previamente no reportada en cánidos. La terapia antimicótica tópica con peróxido de benzoílo consiguió la remisión clínica y micológica de las lesiones.

\section{REFERENCIAS}

Abid HN, PA Walter, H Litchfield. 1987. Chromomycosis in a horse. J Am Vet Med Assoc 191, 711-712.

Bube A, E Burkhardt, R Weiss. 1992. Spontaneous chromomycosis in the marine toad (Bufo marinus). J Comp Pathol 106, 73-77.

De Hoog GS, J Guarro, J Gené, MJ Figueras. 2000. Atlas of Clinical Fungi. Centralbureau for Schimmelcultures, NetherlandsUniversitat Rovira et Virgili, Spain.

Fondati A, MG Gallo, E Romano, D Fondevila. 2001. A case of feline phaeohifomycosis due to Fonsecaea pedrosoi. Vet Dermatol 12, 297-301.

Iwatsu T, M Miyaji, S Okmoto. 1981. Isolation of Phialophora verrucosa and Fonsecaea pedrosoi from nature in Japan. Mycopathologia 75, 149-158.

Juopperi T, K Karli, R De Voe, CB Grindem. 2002. Granulomatous dermatitis in a spadefoot toad (Scraphiopus holbrooki). Vet Clin Pathol 31, 137-139.

Kwon-Chung KJ, JE Bennett. 1992. Chromoblastomycosis. En: KwonChung KJ, Bennett JE. Medical Mycology. Lea \& Febiger, Philadelphia, USA, Pp 337-355. 
Mujica F, C Vergara, E Oehrens E. 1980. Flora Fungosa Chilena. Editorial Universitaria, Santiago.

Oddó D, T Lobos. 1988. Micosis inhabituales en Chile: comunicación de 10 casos. Rev Med Chile 116, 1135-1142.

Piontelli E, MA Toro, L Salamanca, MC Díaz. 1982. Algunas dematiáceas de interés médico aisladas de material clínico y otros ambientes. Bol Micol 1, 213-224.

Piontelli E, MA Toro. 1987. Los animales domésticos (perros y gatos) como reservorio fúngico. Bol Micol 4, 149-158.

Salgado CG, JP Silva, JAP Diniz, MB Silva, PF Costa, C Teixeira, UI Salgado. 2004. Isolation of Fonsecaea pedrosoi from thorns of
Mimosa pudica, a probable natural source of Chromoblastomycosis. Rev Inst Med trop S Paulo 46, 33-36.

Sidrim JJC, AML Filho, V Bandeira. 2004. Cromomicose e feohifomicose. Em: Sidrim JJC, Rocha MF (eds). Micologia Médica. A Luz de Autores Contemporaneos. Guanabara Koogan AS, Rio de Janeiro, Brasil, Pp 198-203.

Silva V, P Godoy. 2004. Tinea nigra. En: Sidrim JJC, Rocha MF (eds). Micologia Médica. A Luz de Autores Contemporaneos. Guanabara Koogan AS, Rio de Janeiro, Brasil, Pp 124-128.

Simpson JG. 1966. A case of chromoblastomycosis in a horse. Vet Med Small Anim Clin 61, 1207-1209. 